\title{
Is Leave for Fathers Pronatalist? A Mixed-Methods Study of the Impact of Fathers' Uptake of Parental Leave on Couples' Childbearing Intentions in South Korea
}

\author{
Youngcho Lee ${ }^{1}$ D
}

Received: 1 June 2021 / Accepted: 6 January 2022 / Published online: 15 January 2022

(c) The Author(s) 2022

\begin{abstract}
While many countries with low birth rates have implemented policies incentivizing fathers to take parental leave with the anticipation that it will contribute to raising birth rates, there is scant research empirically testing whether fathers' uptake of leave is pronatalist. Existing research is limited to a few European (mostly Nordic) countries, and it is unclear whether there exists a positive causal relationship. Using mixed methods, this paper seeks to explore the processes and mechanisms by which fathers' uptake of parental leave impacts intentions for additional children in South Korea, a country characterized by lowest-low fertility and low but rapidly expanding uptake of leave by fathers. Results based on multinomial logistic regression models suggest that in comparison to fathers who expect to take their first leave shortly, fathers with leave experience are less likely to report couple-level intentions for another child, significantly so at parity two. Interviews of fathers with parental leave experience confirm that fathers attenuate their fertility intentions downwards in light of the difficulties of childcare during their leave. While these intentions may change further down the line and/or couples may decide to continue an unplanned pregnancy, results suggest that fathers' parental leave has an anti- rather than pronatalist effect in South Korea. This study demonstrates that in countries with poor support for the reconciliation of employment and childcare, equalizing the gendered division of parental leave may not be sufficient to see a reversal in its fertility trends.
\end{abstract}

Keywords Fathers · Parental leave $\cdot$ Gender equality · Fertility · Gender revolution · South Korea

Youngcho Lee

yl670@cam.ac.uk

1 Department of Sociology, University of Cambridge, 16 Mill Lane, Cambridge CB2 1SB, UK 


\section{Introduction}

Policymakers and researchers of countries with birth rates well below the replacement level have been paying increasing attention to parental leave policies as a way to address both domestic gender relations and childbearing decisions. Gender equality theories of fertility suggest that promoting gender equality within the home and supporting the reconciliation between work and family life by incentivizing fathers to take parental leave through incentives and quotas will ultimately encourage more childbirths. Some governments promote fathers' leave policies with an explicit pronatalist objective, while for other governments, the pronatalist angle is more tacit and takes a back seat to the more feminist objectives of equalizing the division of care labor within the family and making it easier for women to balance paid and unpaid labor. In both cases, the impact of parental leave policies on childbearing behaviors in low-fertility settings is of great interest to politicians and academics alike.

However, whether fathers' uptake of parental leave does have pronatalist consequences or not is an empirical question that has not been sufficiently tested, especially outside Scandinavia. Furthermore, even though some studies find a generally positive association between fathers' uptake of leave and second births, this is not confirmed in a recent study which examines whether a causal relationship exists. This paper extends existing studies to study how fathers' uptake of parental leave could impact the couplelevel intentions for an additional child in South Korea, a lowest-low-fertility country with poor work-family balance and high levels of inequality in the gendered division of domestic labor. I do this based on a mixed-methods analysis of unique online survey and interview data. In the quantitative analysis, I try to separate the effect which could be explained by the experience of being on parental leave by directly comparing the couple-level childbearing intentions of fathers with parental leave experience and fathers who expect to take their first leave shortly. I triangulate the quantitative findings with qualitative narratives of whether and how parental leave experience had any influence on the desire for more children, based on interviews with 51 fathers with parental leave experience. Results from both quantitative and qualitative analyses suggest that fathers' uptake of leave has more of an anti- rather than a pronatalist effect on intentions for further children.

In the following sections, I will first give an overview of the theoretical and empirical literature on gender equality, fertility, and "Fathers' Uptake of Parental Leave." Then I will introduce the South Korean setting, followed by the "Data and Methods" for this study. After presenting the "Findings" from the quantitative and qualitative analyses, I will end with some discussions, including limitations and implications of this research and suggestions for future research. 


\section{Fathers' Uptake of Parental Leave, Gender Equality, and Fertility}

\section{Rethinking Theories of Gender Equality and Fertility}

McDonald's seminal work (2000a, 200b, 2006, 2013) explains very low levels of fertility as a by-product of the tensions resulting from discrepancies in women's positions in the family vis-à-vis individual-oriented institutions. Because the effect of childbearing is greater for women than men, women tend to be more risk-averse about having (more) children. Hence, when women deem their roles as wives/mothers to be incompatible with their career aspirations, they opt out from (additional) childbirths. Then, it follows, equalizing the family sphere to allow women to combine employment with childcare can uplift women's desires for (more) babies. While McDonald is not explicit on how a more gender-equal family institution will influence the fertility intentions of the men in the relationship, he seems to assume either that men will agree to their female partners' increased fertility desires or that men never wanted fewer children than their female partners did.

More recently, Goldscheider, Bernhardt, and Lappegård's have proposed the "gender revolution" framework (2015) to understand childbearing decisions. They theorize that with the first stage of the gender revolution, women increasingly enter employment, but with little relief from domestic duties. Women's "second shift" increases the pressure in balancing work and family life, resulting in depressed desires for (more) children. In the second half of the gender revolution, it is men who must transform by increasing their involvement within the home to relieve some of the burdens of their female counterparts. Here, Goldscheider, Bernhardt, and Lappegård suggest that egalitarian and/or family-oriented men who are more domestically involved will also incline towards having more children. Hence, the completion of both stages of gender revolution will give way to a more egalitarian equilibrium, allowing high female employment levels to coincide with near-replacement level fertility rates, while an "incomplete" revolution will lead to low birth rates (Esping-Andersen and Billari, 2015).

These gender equality theories of fertility commonly assume that there will exist a consensus between the couple for more children. However, this may not necessarily be the case. There may be a lack of any causal link between male uptake of parental leave and fertility because it is selection rather than causality that is driving the relationship between parental leave and continued childbearing. Male uptake of (long) parental leave is considered, to varying degrees in different contexts, to be a selective process. Hence, it could be men whose division of paid and unpaid work with their female partners is already relatively equitable and/ or those hoping to have more children in the first place who opt into (long) parental leave. It could also be that fathers' leave is taken up by the male partners of career-driven women who do not plan to have multiple children. While a negative association between fathers' uptake of leave and fertility may be found in this case, it would again be selection rather than causation that drives the relationship.

Alternatively, fathers' uptake of leave could contribute little to the increase in, or even lead to the downward adjustment of, the couple-level fertility intentions. 
This is because childbearing decisions are a result of the joint consensus between the couple reached at the end of a dyadic process, possibly laden with disagreements (Testa \& Bolano, 2021). Men alleviating their female partners of some of their domestic burdens may in turn result in men may now facing greater constraints in reconciling paid work and family life. In this case, men's uptake of parental leave and greater contribution to domestic duties may depress rather than uplift men's fertility desires. Then it follows, even if women may want more children, their male partners may not reciprocate, and the couple-level consensus needed for additional births may lack (Okun \& Raz-Yurovich, 2018).

Moreover, these various explanations of the relationship between fathers' uptake of leave and fertility may not necessarily be mutually exclusive. That is, different relationships may be observed for different parity or sub-groups of the population, and a selection effect and causal effect may simultaneously be observed. In this vein, the theories predicting domestic gender equality to drive up fertility do not seem to sufficiently account for the multiple, complex, and dyadic mechanisms which could mediate the relationship between fathers' uptake of leave (and gender equality more generally) and continued childbearing. Having discussed how the theoretical explanations of fathers' uptake of leave on fertility could be reconsidered, I now turn to review what the empirical literature examining this relationship finds.

\section{Empirical Studies of Fathers' Uptake of Parental Leave and Fertility}

There are extensive, though not necessarily consistent, bodies of literature on the relationship between fathers' uptake of parental leave and division of domestic labor on one hand (for examples of up-to-date research see Bünning, 2015; Patnaik, 2019; Schober, 2014; Tamm, 2019; Wray, 2020) and division of domestic labor and fertility on the other hand (for an up-to-date review of the literature see Raybould \& Sear, 2020).

In contrast, there exists only limited research which examines the direct relationship between male parental leave uptake and fertility, and most of these works do not make a causal claim. Existing works document a positive association between fathers' uptake of leave and second births in Sweden, Norway, and Iceland, but results are inconclusive for Hungary (Duvander \& Andersson, 2006; Duvander et al., 2010, 2019; Oláh, 2003). Findings are mixed for third births, due in part to differences in research design; some confirm a weaker but still positive association (Duvander \& Andersson, 2006; Duvander et al., 2010), but Lappegård (2010) and Duvander et al. (2019) find a reversed association. Moreover, some of the positive association disappears or weakens for the longest category of leave uptake, calculated as more than 25\% of leave benefit per earnings in Duvander and Andersson (2006), as more than $75 \%$ in Duvander et al. (2010), and as more than the quota in Duvander et al. (2019), respectively. In short, there are variations in the relationship between fathers' uptake of leave and parity progression by the parity, length of leave, as well as country context.

Further to this, a few studies offer a causal analysis of fathers' uptake of leave on fertility based on quasi-natural experiments made possible by reforms 
in fathers' leave policy. Two studies, each by Cools et al. (2015) and Hart et al. (2019) find no evidence that paternity leave affects fertility in Norway. A recent publication by Duvander et al. (2020) similarly finds that the introduction of father's leave quotas did not affect fertility in Norway while it finds a positive but temporary effect only on third-birth risks for lower-income couples in Sweden. On the other hand, Farré and González (2019) find that the introduction of 2 weeks of paternity leave in Spain led to a decrease in men's desired fertility as well as delays in subsequent fertility, which in part also led to reduced parity progression for older couples. Farré and González (2019) further suggest two complementary explanations for the negative causal pathway: the fathers' increased involvement in childcare having led to an increase in the mothers' labor force attachment, and/or that men's increase awareness of the costs of childrearing led to a shift in preferences from child quantity to quality.

Of course, as the authors of Duvander et al. (2020) caution, witnessing the effects of policy reforms often takes some time, and thus, further investigation is merited with more diverse follow-up studies. Nonetheless, it is interesting that the generally consistent positive association between fathers' leave and risks for second births which the earlier studies document is not confirmed in these causal studies. These diverging findings suggest that the presence of a positive association may not necessarily be taken as evidence of a positive causal impact of fathers' uptake of leave, because fathers wanting another child may have selfselected into (long) parental leave after the birth of the first child. While the prominence of such selection effects is acknowledged in most studies of fathers' uptake of leave comparing fathers with leave experience to those without, Pailhé et al. (2018) addresses selection effects via "the comparison of takers (those who have already taken the leave) and future takers (those who will take the leave but have not yet taken it)" (22). They suggest, "the underlying idea being that those two categories of fathers are not different in terms of unobserved heterogeneity once all the observed characteristics are taken into account" (23).

It should, furthermore be emphasized that most of the limited studies that explore the relationship between fathers' uptake of leave and fertility document Nordic contexts. The Nordic countries are often grouped as social democratic welfare regimes with high levels of gender equality as well as generous welfare policies to support families, in comparison to the rest of the world. The Nordic countries typically also have the longest histories when it comes to fathers' uptake of leave and the majority of fathers in these countries tend to take some amount of leave. In this vein, it is particularly noteworthy that the findings from the two non-Nordic countries-Hungary (Oláh, 2003), a post-socialist country which is characterized by pro-work conservative gender role norms and poor work-family reconciliation policies, and Spain (Farré \& González, 2019), a familiaristic Southern European welfare state with low levels of female labor force participation, are not consistent with those of Nordic countries. This suggests that the relationship between fathers' uptake of leave and fertility is very much contingent on social policy configurations and gender and cultural norms and institutions. The small number of studies on limited country contexts merits more studies on the relationship between fathers' leave and fertility, in diverse country settings. 
Addressing such prior contributions and gaps, this paper seeks to examine the relationship between South Korean fathers' uptake of parental leave and intentions for subsequent children. By using a mixed-methods research design to study fertility intentions, I seek to enhance our understanding of how the fathers' parental leave experience factors in the processes that lead couples to form decisions about childbearing. In the following section, I first discuss the South Korean social and institutional setting, highlighting how South Korea offers an interesting and apt context for this study.

\section{Low Fertility and Leave for Fathers in South Korea}

\section{The South Korean Social and Institutional Context}

South Korea is an archetypal developmental familial welfare state in which much of the responsibility to provide care to dependents has historically fallen on (the women of the) families, rather than the state. Even with welfare expansions in the past couple of decades (Kim \& Choi, 2012), the provision of public childcare service is low in Korea, with only 17\% enrolled in public childcare in 2019 (Statistics Korea, 2020a). The demand for a place in public childcare far exceeds supply because public childcare is more affordable and considered to be more reliable compared to its private counterpart. According to a 2018 study, parents of young children under six reported waiting an average of 7.6 months for a place at a public childcare facility, 9.2 months in the case of those residing in large cities (Lee et al., 2018).

South Koreans also work some of the longest hours among OECD member states, working an average of roughly ten more hours each week than those in Norway, Sweden, or Iceland, which are among the countries with the shortest working hours (OECD, 2021a). In South Korea, a 52-h-per-week limit on working hours has been passed only in 2018 (and enforced in most companies from 2021), before which it was legal to work up to 68 weeks per week. This means dual-earner parents of nuclear families commonly struggle to juggle employment and childcare, especially without the help of extended family members.

To make matters worse for women, the gendered division of unpaid work is highly unequal, with Korean wives spending four times the amount of time than husbands on average, 3.5 times even in the case of dual-earning couples (Statistics Korea, 2020d). From a comparative perspective, the average time Korean men spend in unpaid labor is smaller than one third of what men in Finland, Norway, and Sweden do (OECD, 2021b). Due to having to balance most of the domestic labor with paid employment, Korean women face serious structural disadvantages in the labor market, with women's employment by age represented as an accentuated M-shaped curve which illustrates career discontinuity in women's thirties and forties (Statistics Korea, 2020e).

Such strains in balancing paid work and family life make it difficult for women to (get married and) have multiple children, let alone just one child. The ideal number of children has been relatively stable over the past few decades and not falling below two for married women in prime childbearing ages (KIHASA, 2019), but South 
Korea's TFR (total fertility rate) has been consistently below 1.5 since the turn of the century and still on the decline. Increasingly more people are remaining single and more couples remaining childless after marriage. Among those who do go on to become parents, more than half opt to have just one child, while less than $40 \%$ have two children and only around $10 \%$ three or more (Lee, 2017). Today, South Korea has the lowest fertility worldwide, with its TFR hitting an all-time rock bottom of 0.84 in 2020 (Statistics Korea, 2021b). Alarmed politicians and policymakers have rushed to introduce various family support policies to remedy declining birthdates but with little success. The introduction and expansion of parental leave benefits and incentives targeting fathers in recent years can also be understood as motivated by sentiments of urgency surrounding low fertility and population aging.

\section{Fathers' Uptake of Parental Leave in South Korea}

While parental leave policy existed in Korea since 1987, it was originally unpaid and only for female workers. Legislative amendments in 2001 introduced a paid component as well as the inclusion of male workers in its eligibility criteria. In 2014, a "fathers' month" system was introduced, guaranteeing a maximum of 1,500,000 won (approximately \$1250) for the first month to the second parent to take leave for a child - the father in most cases. As a result of incremental expansions in coverage, today Korean parents can take up to 12 months of non-transferable parental leave for each child of 8 years old or under and the second parent to take leave receives up to 2,500,000 won (approximately \$2090) in the first 3 months and up to 1,200,000 won (approximately \$1000) in the following months. South Korea provides the longest length of non-transferable parental leave for fathers in the OECD, much longer than Sweden and Iceland's 13 weeks or Norway's 10 weeks (OECD, 2019). However, the average income replacement rate over the total duration of leave comes down to a mere $29.3 \%$ of national average earnings, only a portion of that in Norway $(94.2 \%)$, Sweden (75.7\%), and Iceland (68.2\%) (OECD, 2017).

Despite the modest levels of benefits, the number of fathers taking up parental leave has rapidly increased in the last few years, as Table 1 documents. The ratio of male users of parental leave has quadrupled, from 5\% in 2014 to $20 \%$ in 2019 (Statistics Korea, 2020c). Furthermore, in Korea parents tend to take very long leaves, of more than 200 days in the case of fathers (see row (h)). This is substantially longer than the average days used by fathers in Sweden (131 days), Iceland (70 days), and Norway (40 days) (NOSOSCO, 2017). Nonetheless, even with the recent progress, rows (b), (d), and (e) demonstrate that fathers who take parental leave constitute a minority of total eligible fathers in South Korea, even when considering that the figures do not account for the majority of fathers who take leave after their child's first birthday (Statistics Korea, 2020c). This contrasts with how the majority of eligible fathers take some leave in Nordic countries such as Sweden, Norway, and Iceland (International Network on Leave Policies and Research, 2019).

In sum, South Korea is characterized by the lowest fertility in the world, a highly gendered division of domestic labor and poor work/family balance. Moreover, South Korean parental leave policies are among the most flexible and generous in terms of 


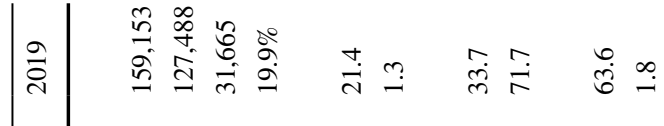

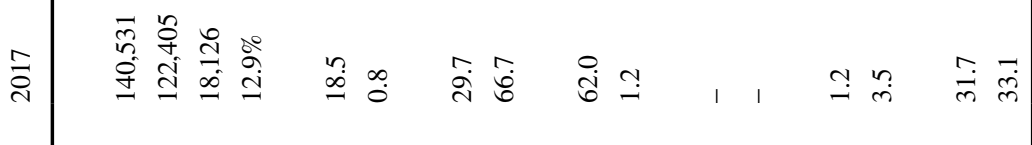

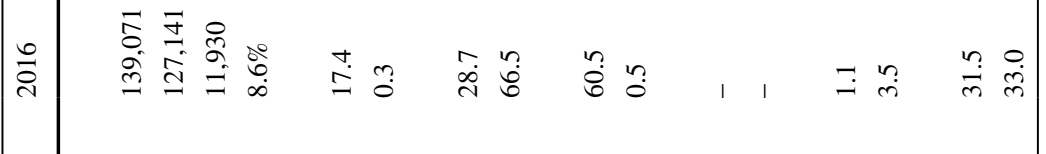

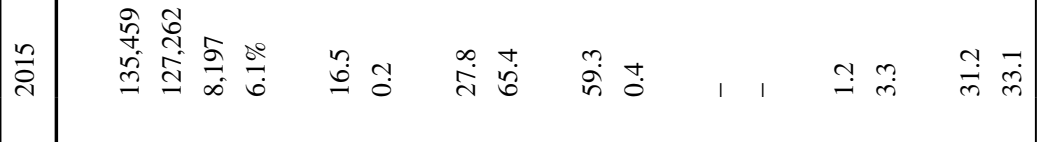

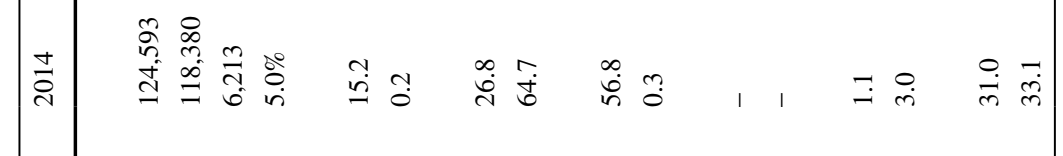

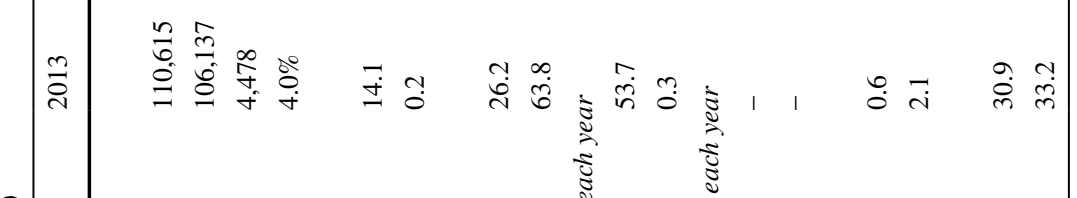

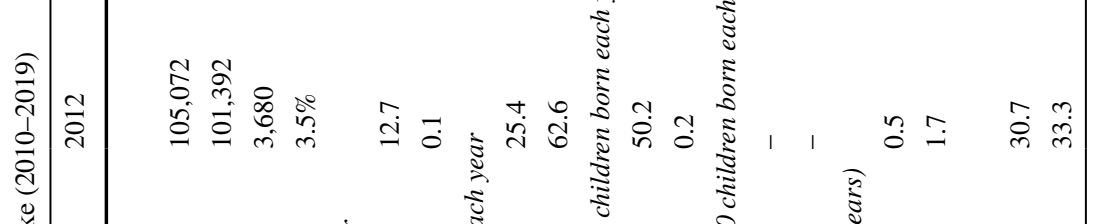

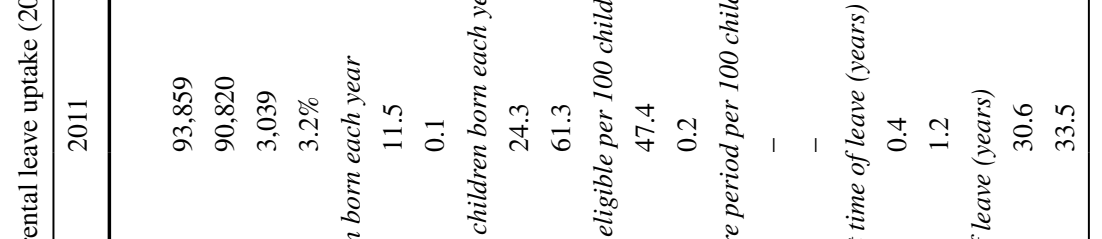

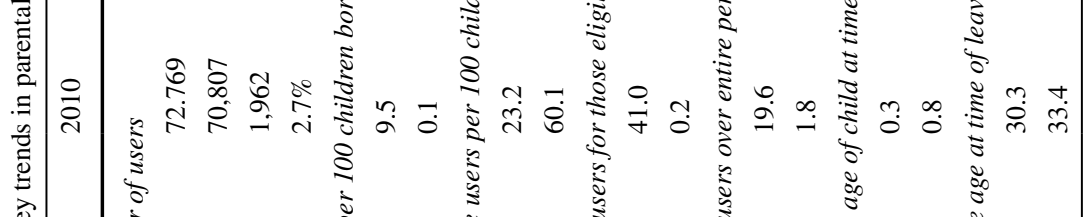

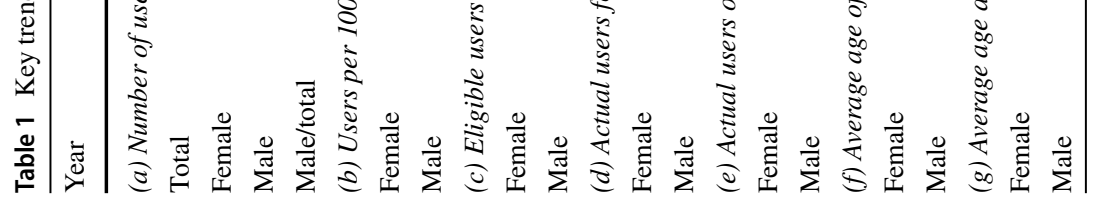




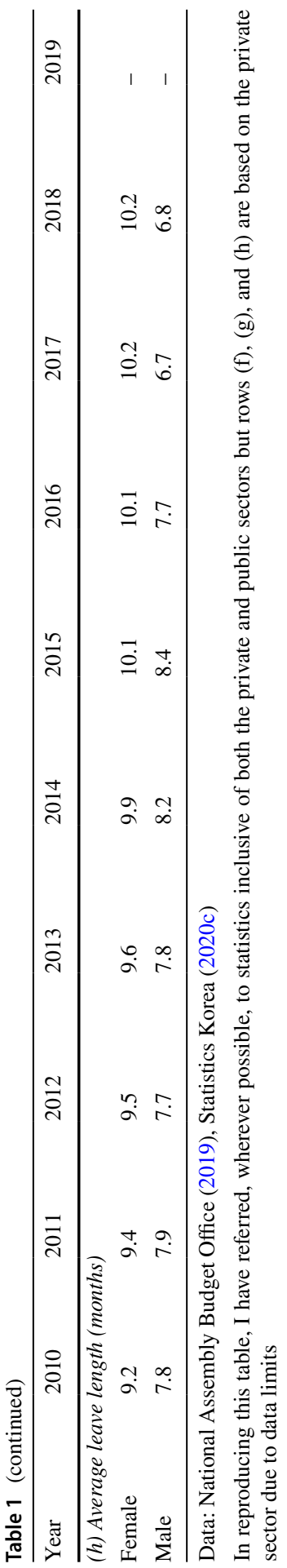


duration but not income replacement rate. Nevertheless, increasingly more fathers are choosing to take up leave, and often for considerable durations. This offers a timely and distinct context to examine the relationship between fathers' uptake of parental leave and fertility. Next, I turn to introduce the data and methods used for this mixed-methods research.

\section{Data and Methods}

This research utilizes both quantitative and qualitative data ${ }^{1}$ and methods to study the relationship between fathers' parental leave experience and couple-level intentions for an additional child in South Korea. Consistent with the findings from Spain (Farré \& González, 2019), I hypothesize that Korean fathers will also report a lower intention for another child if they have experienced fathers' leave. I further hypothesize that this is driven not by the selection of fathers with lower fertility intentions choosing to take leave, but rather due to fathers adjusting their fertility intentions downwards after their leave experience. While the quantitative analysis will focus on comparing the fertility intentions of fathers with different leave experience, the qualitative analysis will seek to understand the various contextual factors which shape changes in fathers' fertility preferences.

\section{Data and Methods for Quantitative Analysis}

The quantitative data for this study is based on a Qualtrics web survey which employs a non-probability sampling strategy. It targets married fathers with at least one child who is seven or younger, especially those with experience of or plans to take parental leave. I mainly advertised and distributed the survey through online platforms for parents with young children such as parenting cafes and blogs and attracted participants with a random gift coupon draw. The survey is composed of four substantive sections each asking about the respondent's family and demographic background, employment, division of domestic labor, and views on the family and gender roles. The survey was designed to be as succinct as possible to minimize participant fatigue, and as a result, it took most respondents less than ten minutes to complete the survey. Of all responses collected from May 2020 to March 2021, this research draws on a sub-sample $(N=1042)$ of those with either one child $(N=632)$ or two children $(N=410)$ to examine their intention for an added child. This sample includes a small number of fathers whose youngest child is older than seven $(n=31$, $2.98 \%$ ), but there are no indications that the inclusion of these respondents influences the results.

Due to the way the data is collected, the sampled fathers are not representative of fathers in the general population. Respondents who would be browsing online parenting communities, showing interest in the research advertisement, and completing

\footnotetext{
${ }^{1}$ I confirm this study obtained ethical approval by the relevant committee at my home institution and all participants granted informed consent and permission for the data to be used for research purposes.
} 
the survey are likely to be fathers with considerable levels of interest and engagement in childcare and family matters. However, there are a few reasons why the use of a non-representative online survey is justified for this research. First, existing secondary data does not allow for an exploration of the relationship between fathers' uptake of leave and fertility. Korean population registers do not have information on the respondents' parental leave use and relevant social survey datasets do not include sufficient cases of fathers with leave experience to allow for statistical comparison, as male parental leave users are still rare in South Korea. Even assuming existing datasets had sufficient cases of fathers with leave experience, they do not allow researchers to untangle the matter of selection, as we are unable to distinguish whether additional childbirth is a result of the father taking leave or not. In contrast, the survey being used for this research was designed in such a way to distinguish between fathers by whether their leave is ongoing, completed, expected, or none of these. In addition, Ito and Todoroki (2020) suggest in their recent paper that multivariate analysis reduces the discrepancies between results based on online survey data and those based on representative data. As such, while caution is required in generalizing the findings to the population level, the use of a non-representativeness dataset was not only an inevitable but also a strategic decision to research a small and atypical population, such as South Korean leave-taking fathers. Now I turn to discuss the operationalization of key variables.

\section{Intention for Another Child}

The dependent variable in this research is the couple's intention to have another child, derived from the question, "Do you and your wife have plans for another child?" Three responses were possible: "yes," unsure, "or no." In the multinomial logistic regressions, I used the "no" response as the reference category to compare the different fathers' relative risk of answering "yes" and "unsure," respectively. ${ }^{2}$ Due to the way, this question was worded, the responses are understood to represent the joint intention of the couple, rather than the father's individual-level fertility desire. Fertility intentions or plans are considered to provide reasonable indications of actualized fertility because intentions are results of desires that are limited by reality. Existing studies suggest that the gap between actual and intended fertility is relatively minor in comparison to the bigger gap between intended and desired fertility (Chen \& Yip, 2017; Livi-Bacci, 2001; Miettinen et al., 2011; Sobotka \& Beaujouan, 2014). On the other hand, a limitation of the wording of the question is that it does not specify fertility plans within a short timespan (e.g., the next 1 or 3 years). As prior studies point to the importance of short and specific time windows

\footnotetext{
${ }^{2}$ Because I am running a multinomial logistic regression for a categorical dependent variable with more than two possible outcomes that have no natural order ('yes,' 'unsure,' and 'no') as opposed to running ordinal logistic regression for a binary variable, I report relative risk ratios (RRR) rather than odds ratios (OR) to represent the exponential form of the estimated logistic coefficients. Here, relative risk measures the ratio of the probability of an event occurring in an exposed group (in this case, for fathers who are on or have taken leave) versus the probability of the event occurring in an unexposed group (in this case, the fathers who plan to take their first leave).
} 
in fertility intentions predicting actual behaviors (Billari et al., 2009; Philipov et al., 2006; Schoen et al., 1999), questions not accounting for temporal specificity may fall somewhat short of accurately predicting fertility behaviors. At the same time, the fathers in the sample were on average in their mid to late thirties with their youngest child around 3 years old. Because this places the participants of this research at a critical time when they are most likely to consider and have realistic plans whether to have another child or not, we may infer the responses of these fathers regarding plans for another child to more closely mirror their actual childbearing outcomes than that of a younger population (Morgan \& Rackin, 2010). In short, fertility intentions without temporal specificity are practical but not perfect proxies for fertility outcomes.

\section{Fathers' Uptake of Parental Leave}

For the main independent variable, fathers were asked which of the following best describes their leave experience: "currently on leave," "have taken leave in the past," "have never taken leave yet, but plan to in the near future" (reference category), and "have not and will not take leave." The questionnaire did not ask fathers about their number of leaves taken and, thus, I could not distinguish between those who have taken multiple as opposed to a single leave or whether those who are currently on leave have also taken leave in the past. However, the third option was worded to reflect concrete plans for a respondent's first parental leave and, thus, captures fathers with the disposition to choose to take leave before they start their first leave. The fathers who have taken leave in the past were further specified based on how long their leave was short (up to 3 months), moderate (4 to 11 months), and very long (12 months or longer).

My analytic strategy entails taking fathers who "plan to take leave" as the reference category to account for the selection of particular fathers into leave which may drive a considerable part of the difference between fathers with leave experience and those without (for a study utilizing a similar analytic strategy, see Pailhé et al., 2018). In order to separate out the impact of fathers taking leave as much as possible, the groups of comparison must be as similar as possible. Using the fathers who "have not and will not take leave" as the reference group does not allow me to account for such selection effect because I am unable to distinguish whether the difference represents the selection of fathers with certain predispositions into leave or changes as a result of fathers taking leave. On the other hand, using the "plan to take leave" fathers as the reference category allows me to compare the fathers in the reference group with fathers who are 'on leave' as well as fathers who "have taken leave." Here, by directly comparing groups of fathers who share the disposition for parental leave by whether their leave is experienced or expected (but not yet experienced), I am able to separate the effect of experiencing parental leave to an extent. Furthermore, using the "plan to take leave" fathers as the reference category also allows me to compare this reference group of fathers who plan to take their first leave to fathers who "have not and will not take leave." These two groups of fathers both have no leave experience but are distinguished by whether they are predisposed to leave taking. The direct comparison between these two groups allows me to- to 
an extent-isolate the effect of certain fathers' self-selection into leave. This analytic strategy enables me to determine whether it is the selection of fathers with certain predispositions into leave or fathers' experience of taking leave that better explains differences in fertility intentions.

Guided by existing literature, I include key socioeconomic and demographic controls such as the age, education, and income of the father and his wife. I further control for variables that could be related to both fathers' uptake of leave and intentions for another child, such as the age of the youngest child, whether the wife is pregnant, and the fathers' gender role attitudes. ${ }^{3}$

\section{Data and Methods for Qualitative Analysis}

The data for the qualitative part of the research also came from the fathers who took part in the online survey, wherein the final question invited respondents to indicate interest in a follow-up interview. Among those who expressed interest, I contacted fathers with ongoing or completed parental leave experience and was able to interview a total of 51 fathers between May and October of $2020 .{ }^{4}$ The interviewed fathers were highly diverse in their demographic background and how their leave was taken (see Table 2 for a breakdown of the sample characteristics).

The interviews were semi-structured, conducted either in-person (19), on the phone (24), via email (2) or video call (1), depending on the fathers' preferences and in line with the Covid19 regulations, and most lasted between 40 and 90 min. All interviews were recorded with consent and later transcribed verbatim. While the interviews covered a wide range of questions about the fathers' leave experiences, for this research I draw mainly on discussions related to the respondents' and their wives' childbearing intentions and rationales, how these intentions have shifted over time, and whether and how their parental leave experience had any influence. Specifically, I asked, based on the interviewees' response to the web survey question on intentions for another child, whether and how fathers' leave experience factored in. I furthermore asked interviewees' thoughts on whether promoting fathers' leave is an effective way to address Korea's low fertility.

In thematically analyzing the qualitative data, I conducted multiple readings of each interview transcript, summarized each interviewee's profile and story into

\footnotetext{
${ }^{3}$ I measure fathers' gender roles attitudes by synthesizing their level of agreement (1: strongly agree, 2: somewhat agree, 3: somewhat disagree, 4: strongly disagree) to the following eight statements: (a) it is ideal for the husband to have a career and the wife to care for the home; (b) it is not good for the relationship if the wife earns more than the husband; (c) during an economic recession it is okay to fire women first; (d) if one parent has to quit work to care for the child, it should be the wife; (e) husbands in dual-earning couples should help out with housework under their wives' lead; (f) given the opportunity, men can be as skilled at housework and childcare as women; (g) boys and girls should be raised according to their gender roles; (h) the most important role of a father is to financially provide for the family; (i) one should prioritize his family over his work; and $\mathrm{j}$ ) spending time with my family is a joy rather than a burden. The Cronbach's alpha score for the ten statements is 0.77 , and (after applying appropriate reverse scoring) the synthesized variable can take the value of 1 (least egalitarian gender role attitudes) to 26 (most egalitarian gender role attitudes).

4 This meant the interviews were conducted simultaneously with the data collection for the web survey.
} 
Table 2 Composition of interviewed fathers by key characteristics $(N=51)$

\begin{tabular}{lrll}
\hline Employment & & Age (mean, range) & $38(27-42)$ \\
Public sector & 21 & Age of youngest (mean, range) & $3(0-8)$ \\
Large private company & 5 & Number of children & 19 \\
Small/medium private company & 13 & One & 28 \\
Non-profit sector & 8 & Two & 4 \\
Freelance or self-employed & 3 & Three & $13(2.5-36)$ \\
Not in employment & 1 & Months of leave (mean, range) & \\
Division of paid work & & Number of leave & 46 \\
Dual-earner couple & 45 & Once & 4 \\
Single-earner husband & 5 & Twice & 1 \\
Single-earner wife & 1 & Thrice & \\
Education & & Solo or joint leave & 45 \\
Secondary & 1 & Solo leave & 4 \\
2-year college & 4 & Joint with wife & 2 \\
4-year university & 38 & In-part overlapping with wife & \\
Graduate degree & 8 & Leave ongoing or finished & 32 \\
Monthly household income & & Finished leave & 15 \\
Under 5,000,000 won $(\$ 4175)$ & 16 & On first leave & 4 \\
Over 5,000,000 won $(\$ 4175)$ & 35 & On second or third leave & \\
\hline Based & & & \\
\hline
\end{tabular}

Based on the current information of the fathers, not information at the time of their leave

a short memo, and coded each interview to identify recurring themes. I also color coded and compiled the responses related to fertility intentions into a separate file for a more focused reading and analysis. This way, I was able to zoom in and out of the data, focusing on the responses most relevant to childbearing intentions while also keeping in mind the overall accounts that the fathers gave of their parental leave experience, including the contextual circumstances that could shape childbearing intentions. Supplementing the quantitative findings with qualitative interviews enabled me to gain a holistic understanding of not just "what" but also "why" respondents demonstrate certain demographic intentions, which is a strength of this mixedmethods study.

\section{Findings}

\section{Descriptive Statistics}

Table 3 sums up the key demographic characteristics of the 1042 fathers in the sample by their parental leave status. The average respondent was a 37 -year-old father with a youngest child around 3 years old. While three quarters of fathers with plans to take their first leave soon had just one child compared to 50 to 63 in the other groups, these fathers also had the highest ratio of those whose wives were pregnant, which meant they were expecting another child shortly. Of the 
Table 3 Key demographic characteristics of fathers with one or two children, by leave status

\begin{tabular}{|c|c|c|c|c|c|}
\hline & On leave & Have taken & Plan to & No leave & Total \\
\hline Mean age of fathers & 36.17 & 37.20 & 35.78 & 37.10 & 36.78 \\
\hline Mean age of wives & 34.32 & 35.49 & 33.39 & 34.79 & 34.67 \\
\hline Mean age of youngest & 2.93 & 3.90 & 2.52 & 3.54 & 3.38 \\
\hline \multicolumn{6}{|l|}{ Number of children (\%) } \\
\hline One & $54.61 \%$ & $50.61 \%$ & $75.78 \%$ & $62.66 \%$ & $60.65 \%$ \\
\hline Two & $45.39 \%$ & $49.39 \%$ & $24.22 \%$ & $37.34 \%$ & $39.35 \%$ \\
\hline Wife is pregnant (\%) & $11.84 \%$ & $8.10 \%$ & $16.77 \%$ & $9.75 \%$ & $10.75 \%$ \\
\hline \multicolumn{6}{|l|}{ Father's leave length } \\
\hline Short ( 3 months) & & $31.09 \%$ & & & \\
\hline Moderate (4 11 months) & & $39.08 \%$ & & & \\
\hline Long (12 months ) & & $29.83 \%$ & & & \\
\hline Father university degree $^{a}$ & $80.26 \%$ & $81.78 \%$ & $86.34 \%$ & $65.98 \%$ & $74.95 \%$ \\
\hline Wife university degree & $82.24 \%$ & $79.35 \%$ & $80.12 \%$ & $67.63 \%$ & $74.47 \%$ \\
\hline \multicolumn{6}{|l|}{ Wife is currently... } \\
\hline Working & $59.21 \%$ & $55.87 \%$ & $39.75 \%$ & $35.48 \%$ & $44.44 \%$ \\
\hline On leave from work & $19.08 \%$ & $16.19 \%$ & $41.61 \%$ & $19.50 \%$ & $22.07 \%$ \\
\hline Economically inactive & $21.71 \%$ & $27.94 \%$ & $18.63 \%$ & $45.02 \%$ & $33.49 \%$ \\
\hline Mean joint income ${ }^{c}$ & 575.00 & 576.92 & 570.19 & 509.96 & 544.63 \\
\hline Mean father income & 338.82 & 350.20 & 347.83 & 366.18 & 355.57 \\
\hline $\mathrm{N}$ & $152(14.59 \%)$ & $247(23.70 \%)$ & $161(15.45 \%)$ & $482(46.26 \%)$ & $1042(100 \%)$ \\
\hline
\end{tabular}

Income unit is 10,000 won $(\$ 8.35)$

aThe population-level university entrance rate in the 2000's (which is when those in their mid-thirties would have gone to university) ranges between 68 and 84\% (Statistics Korea, 2021a)

${ }^{\mathrm{b}}$ The population-level employment rate for women with children under 7 is $48.1 \%$ (Statistics Korea, 2020e)

${ }^{\mathrm{c}}$ The population-level monthly median wage in 2021 is approximately 4,000,000 won (\$3340) for a threeperson household and 4,900,000 won (\$4090) for a four-person household (Statistics Korea, 2020b)

fathers who have taken leave, around $30 \%$ took relatively short leaves of up to 3 months, another $30 \%$ very long leaves of 1 year or longer, and the remaining took leaves of moderate periods in between. The three groups of fathers with either leave experience or plan are roughly homogenous in their level of education, whether they were single or dual earners, and their household and individual income. In comparison, the fathers with neither leave experience nor plan had a higher ratio of those without a university degree, single earners, and a higher mean individual income but lower mean household income than their counterparts. The relatively high individual income of fathers in the "no leave" group appeared to be driven mainly by a small proportion (around 5\%) of fathers who belonged to the highest income category (more than 7,500,000 won or \$6260). One more thing to note would be that the proportion of wives who are on leave is the highest for fathers who plan to take leave at $42 \%$, which suggests that these 
fathers would be starting their leave when their wives finish theirs, a common arrangement in South Korea.

Figure 1 presents the descriptive statistics documenting the fathers' responses to the couple's intentions for another child by their leave status and parity. For those with one child, the proportion of respondents who indicated no intention for another child was the highest if the father had taken leave, followed by fathers currently on leave, and lowest if he was expecting to take leave shortly. Both the "yes" and "unsure" answers were highest for the group of fathers planning to take leave, indicating both the greatest consensus as well as general openness for an additional child. In the case of parity two, we see a pattern consistent with that of parity one. The proportion of those who indicated plans for another child was highest for the fathers with plans to take leave and lowest for those with no such plans. When comparing parity two with parity one, the "no" responses were markedly higher for all leave-taking categories. This is unsurprising, as it is uncommon for couples to have more than two children in low-fertility settings.

In short, at both parities, there is a pattern of both those with leave experience and those without either leave plan or experience having the lowest intention, while those with plans for leave have the highest intention for another child. I next run a series of multivariate analysis to more systematically test the relationship between fathers' uptake of leave and childbearing intentions.

\section{Multivariate Analysis}

In this section, I conduct multinomial logistic regressions on the risk of responding "yes" and "unsure" to the question on intentions for another child by parity, taking "no (intention)" as the reference category. I present both a main model controlling for the age, education, and income of the father and his wife, the age of the youngest child, and whether the wife is pregnant (Table 4), as well as a model which additionally controls for the father's gender role attitudes (Table 5).

In Table 4, results based on the model on parity one suggest that the relative risk of answering "yes" and "unsure" as opposed to "no" are both lower if fathers have ongoing or past leave experience in comparison to fathers who plan to take their first leave soon (the reference category). However, as these results fall short of the standard level of significance $(p<0.05)$, they must be interpreted with caution. The difference between fathers with neither leave plan nor experience and those who plan to take leave in their intention for a second child is small and insignificant, meaning there is no evidence of a selection effect of fathers intending a second child opting in to leave.

At parity two, results indicate that compared to couples where the father expects to take leave, those where the father has ongoing or completed leave experience report significantly lower risk of positive intentions for another child (the "yes" response). Interestingly, fathers with neither leave experience nor plans are also at a significantly lower risk of intending another child than fathers who plan to take leave. This suggests that while the disposition to take leave is associated with a 


\section{Households with one child ( $n=632$ )}
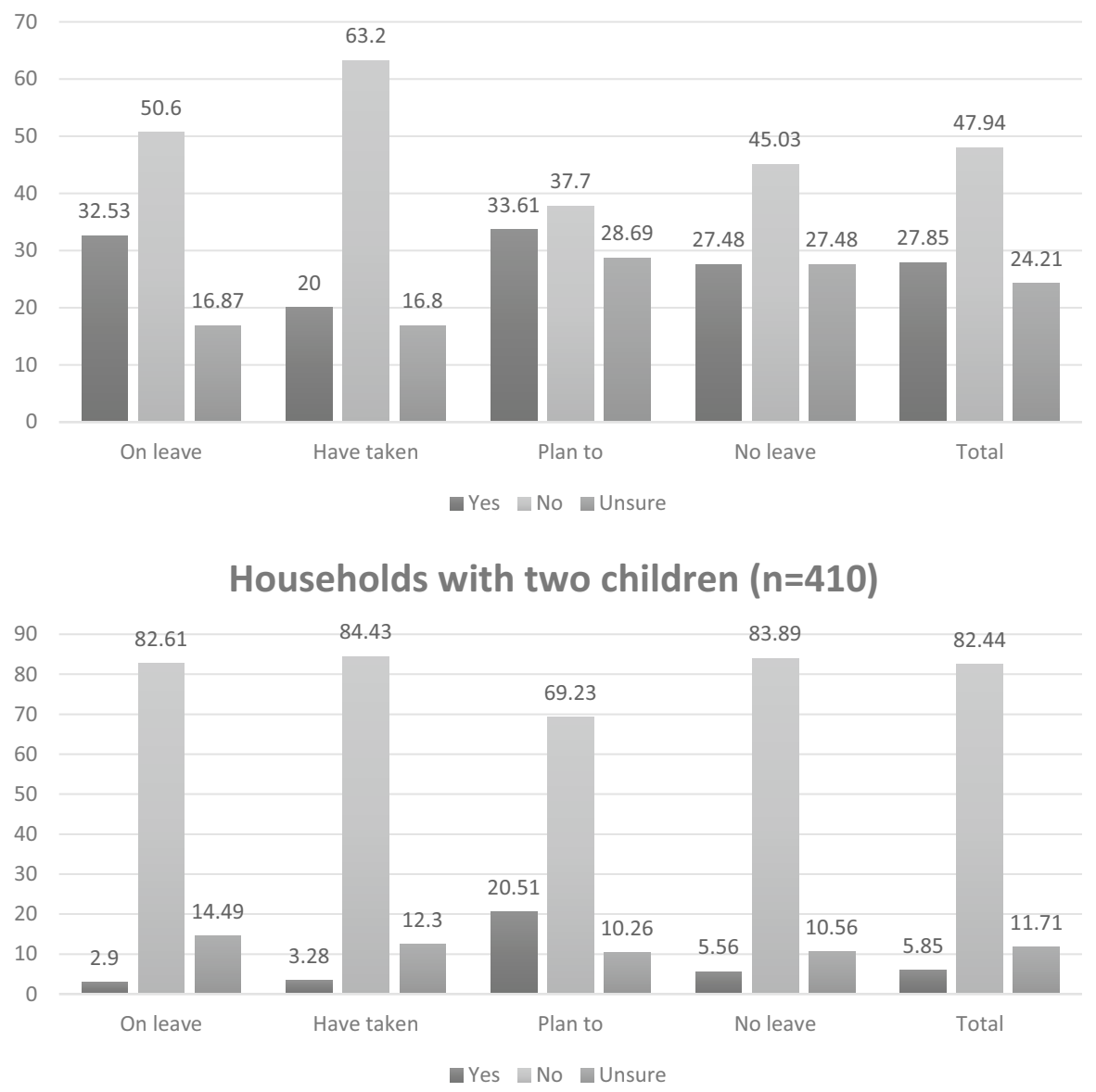

Fig. 1 Couple's intentions for another child (\%), by father's leave status and parity

stronger inclination to intend a third child, the experience of leave taking seems to have the effect of depressing the intention for a third child. Moreover, a significantly lower risk of being "unsure" as opposed to being negative about having a third child is also found for fathers who are currently on leave, but not for fathers who have taken leave in the past or those with neither leave experience nor plans.

In Table 5, I present results additionally controlling for the fathers' gender role attitudes. The added gender role attitudes variable is not significant across all parities. More importantly, the results remain consistent with that of the main model for the most part, with fathers who plan to take their first leave soon (the reference category) being more likely to have another child than both fathers without such plans and fathers with leave experience, significantly so at parity two. 
Table 4 Relative risk ratio (RRR) of the couple's intention for another child by leave uptake (main model)

\begin{tabular}{llllll}
\hline Variables & \multicolumn{2}{l}{ Parity one } & & \multicolumn{2}{l}{ Parity two } \\
\cline { 2 - 3 } \cline { 5 - 6 } \cline { 5 - 6 } & Yes & Unsure & & Yes & Unsure \\
\hline Father's leave: (Reference: plan to take leave) & & \\
Currently on leave & 0.84 & $0.48^{+}$ & & $0.07^{* *}$ & $0.91^{*}$ \\
Have taken in the past & 0.69 & 0.57 & & $0.07^{* * *}$ & 0.90 \\
No experience, no plan & 0.96 & 1.03 & & $0.09^{* * *}$ & 0.84 \\
Father age & 0.98 & 0.98 & & 0.90 & 0.99 \\
Wife age & $0.93^{*}$ & $0.92^{*}$ & & 0.99 & $0.85^{* *}$ \\
Father university degree & 1.11 & 1.01 & & 0.81 & 0.71 \\
Wife university degree & 0.85 & 0.90 & & 1.86 & 0.92 \\
Father income & 1.00 & 1.00 & & $1.00^{+}$ & 1.00 \\
Wife income & 1.00 & 1.00 & & $1.00^{*}$ & $1.00^{+}$ \\
Age of youngest child & $0.69 * * *$ & $0.74 * * *$ & & 0.97 & $0.91^{+}$ \\
Wife is pregnant & 0.70 & $0.17^{* * *}$ & & 1.28 & 0.00 \\
Observations & 631 & & 409 & \\
Pseudo $R$-squared & 0.11 & & 0.14 & \\
\hline
\end{tabular}

$* * * p<0.001, * * p<0.01,{ }^{*} p<0.05,{ }^{+} \mathrm{p}<0.1$

To check whether the relationship between fathers' leave uptake and fertility intentions varies by the length of the leave, I next disaggregated the fathers who have taken leave by the length of their leave: short (up to 3 months), moderate (4 to 11 months), and very long (12 months or longer). Results presented in model 6 find a negative impact on the intention for another child for all but very long leaves at parity one, and a generally significant impact on the intention for another child for at parity two, although the very long leaves fall very slightly short of the 0.05 level of significance $(p=0.056)$. The diverging results for fathers taking very long leaves of 1 year or longer has also been found in previous studies documenting Nordic countries (Duvander \& Andersson, 2006; Duvander et al., 2010), though in opposite directions and may be attributed to the further selectiveness of certain fathers opting into particularly long leave (Table 6).

I conducted a series of robustness checks to ensure the relationship between fathers' leave and fertility intentions remains consistent to alternative model specifications or sample restrictions. I first checked whether the results were robust when treating pregnancy as an additional child by adjusting the observation to parity two where the wife was pregnant in parity one and dropping the observation where the wife was pregnant in parity two (see Table 7). Next, to ensure the results are robust to the age of the youngest child, I ran the main models with restricted samples of those whose youngest child was five or younger and three or younger (see Tables 8 and 9) and next of only the fathers who had taken leave in the past or were expected to take leave in the future for direct comparison (see Table 10). The results from all robustness checks were broadly consistent with the main findings, suggestive of a generally negative effect of parental leave which is statistically significant only at parity two. 
Table 5 Relative risk ratio (RRR) of the couple's intention for another child by leave uptake (addition of the variable on fathers' gender role attitudes)

\begin{tabular}{|c|c|c|c|c|}
\hline \multirow[t]{2}{*}{ Variables } & \multicolumn{2}{|c|}{ Parity one } & \multicolumn{2}{|c|}{ Parity two } \\
\hline & Yes & Unsure & Yes & Unsure \\
\hline \multicolumn{5}{|c|}{ Father's leave: (Reference: plan to take leave) } \\
\hline Currently on leave & 0.83 & $0.36^{*}$ & $0.04 * *$ & 0.90 \\
\hline Have taken in the past & $0.52^{+}$ & 0.56 & $0.07 * * *$ & 0.70 \\
\hline No experience, no plan & 0.84 & 0.90 & $0.08 * * *$ & 0.76 \\
\hline Father age & 0.97 & 0.99 & 0.90 & 0.98 \\
\hline Wife age & $0.93^{+}$ & $0.90 * *$ & 0.99 & $0.86^{*}$ \\
\hline Father university degree & 1.00 & 0.87 & 0.72 & 0.62 \\
\hline Wife university degree & 0.87 & 0.94 & 1.88 & 0.88 \\
\hline Father income & 1.00 & 1.00 & $1.00^{+}$ & 1.00 \\
\hline Wife income & 1.00 & 1.00 & $0.99 * *$ & $1.00 *$ \\
\hline Age of youngest child & $0.73 * * *$ & $0.76 * * *$ & 1.00 & 0.90 \\
\hline Wife is pregnant & $0.60^{+}$ & $0.18 * * *$ & 1.29 & 0.00 \\
\hline Fathers' gender role attitude & 0.99 & 1.00 & 1.03 & 0.99 \\
\hline Observations & 561 & & 373 & \\
\hline Pseudo $R$-squared & 0.11 & & 0.16 & \\
\hline
\end{tabular}

To recap, the findings from quantitative analysis suggest that fathers expecting to take leave are more likely to intend another child than fathers with no such plans at parity two, but not parity one, where there is no significant difference. This suggests that there exists a positive selection effect at parity two only. Moreover, a comparison of fathers with (ongoing or completed) leave experience and those with plans to take fist leave shortly suggests that the former two groups report a lower risk of intending another child, though again this difference is significant only at parity two, suggesting a negative effect of parental leave experience. Although the findings at parity one fall short of statistical significance, the negative relationship should nonetheless be noted. Together, the results suggest that, contrary to the intentions of policymakers and politicians, fathers' leave experience has a generally depressing, rather than uplifting, effect on the intention for another child, especially at parity two. I now turn to examine the findings from the qualitative analysis of the interviews.

\section{Qualitative Findings from Interviews}

None of the interviewed fathers stated that their parental leave experience made them want to have an additional child that they had not wanted previously. Instead, the overall sentiment was that the intensive childcaring experience made them set on having no more children, consistent with the results from the quantitative analysis. The anecdotes below exemplify this, whether the father yearns another but settles for one or simply does not want an additional child. 
Table 6 Relative risk ratio (RRR) of the couple's intention for another child by leave uptake and length

\begin{tabular}{|c|c|c|c|c|}
\hline \multirow[t]{2}{*}{ Variables } & \multicolumn{2}{|c|}{ Parity one } & \multicolumn{2}{|c|}{ Parity two } \\
\hline & Yes & Unsure & Yes & Unsure \\
\hline \multicolumn{5}{|c|}{ Father's leave: (Reference: plan to take first leave shortly) } \\
\hline Currently on leave & 0.83 & $0.48^{+}$ & $0.07 * *$ & $0.89 *$ \\
\hline Have taken short leave $(\sim 3 \mathrm{~m})$ & 0.62 & 0.71 & $0.04 * *$ & 0.44 \\
\hline Have taken moderate leave $(4 \sim 11 \mathrm{~m})$ & 0.45 & 0.60 & $0.04 *$ & 0.85 \\
\hline Have taken long leave $(12 \sim \mathrm{m})$ & 1.09 & 0.41 & $0.17^{+}$ & 1.24 \\
\hline No experience, no plan & 0.97 & 1.04 & $0.09 * * *$ & 0.82 \\
\hline Father age & 0.97 & 0.98 & 0.89 & 0.98 \\
\hline Wife age & $0.93 *$ & $0.92 *$ & 0.99 & $0.84 * *$ \\
\hline Father university degree & 1.10 & 1.01 & 0.76 & 0.68 \\
\hline Wife university degree & 0.86 & 0.89 & 1.70 & 0.78 \\
\hline Household income & 1.00 & 1.00 & $0.99 * *$ & $1.00^{+}$ \\
\hline Individual income & 1.00 & 1.00 & 1.00 & 1.00 \\
\hline Age of youngest child & $0.69 * * *$ & $0.74 * * *$ & 0.97 & 0.91 \\
\hline Wife is pregnant & 0.70 & $0.17 * * *$ & 1.34 & 0.00 \\
\hline Observations & 626 & & 402 & \\
\hline Pseudo $R$-squared & 0.11 & & 0.15 & \\
\hline
\end{tabular}

$* * * p<0.001, * * p<0.01, * p<0.05,{ }^{+} p<0.1$

Originally, we had thoughts about having a second child but I felt too exhausted after raising the child myself. Of course, having another (child) would have been nice... Frankly, I think I did consider (a second child) when I was applying for parental leave, but it being too demanding was why (I changed my mind). - Hojun (father of one)

At first, we were thinking to have at least two kids, but we changed our mind. ... If we have another child one of us would have to quit work because there is no other way... But I did not want either myself or my wife to do that. ... So at the moment, we plan to just raise one well. - Jaebin (father of one)

The more the dad knows more about childcare, they know how exhausting and demanding it is to raise a child. ... The more involved a husband or father is in childcare, (they) don't want additional children. Because it's too much work. I feel that way too. - Jiwon (father of one)

One of the most frequently mentioned sentiments by the interviewed fathers was that they "had no idea looking after a child was this hard." Before their parental leave, most fathers had not experienced being a primary, let alone solo, caregiver for their child, in part because their wives had been on leave. Thus, while the fathers may have originally wanted more than one child in line with the two-child ideal, the leave experience was responsible for the downward attenuation of fertility intentions for these fathers in that it was what opened the fathers' eyes to 
Table 7 Relative risk ratio (RRR) of the couple's intention for another child by leave uptake, treating pregnancy as an additional child

Table 8 Relative risk ratio (RRR) of the couple's intention for another child by leave uptake, restricted sample of fathers whose youngest child is five or younger

\begin{tabular}{llllll}
\hline Variables & \multicolumn{2}{l}{ Parity one } & & \multicolumn{2}{l}{ Parity two } \\
\cline { 2 - 3 } \cline { 5 - 6 } \cline { 5 - 6 } & Yes & Unsure & & Yes & Unsure \\
\hline Father's leave: (Reference: & plan to take leave) & & \\
Currently on leave & 0.89 & $0.43^{+}$ & & $0.17^{* *}$ & 1.03 \\
Have taken in the past & 0.60 & 0.55 & & $0.19^{* *}$ & 1.00 \\
No experience, no plan & 1.01 & 1.09 & & $0.35^{*}$ & 0.88 \\
Father age & 0.97 & 0.99 & & 0.92 & 0.98 \\
Wife age & $0.93^{*}$ & $0.90^{*}$ & & 0.93 & $0.90^{+}$ \\
Father university degree & 1.31 & 1.14 & & 0.99 & 0.67 \\
Wife university degree & 0.91 & 0.97 & & 1.36 & 0.79 \\
Household income & 1.00 & 1.00 & & 1.00 & $1.00^{+}$ \\
Individual income & 1.00 & 1.00 & & 1.00 & 1.00 \\
Age of youngest child & $0.67^{* * *}$ & $0.73^{* * *}$ & 0.93 & 0.87 \\
Observations & 540 & & & 475 & \\
Pseudo $R$-squared & 0.11 & & 0.12 & \\
\hline
\end{tabular}

$* * * p<0.001, * * p<0.01, * p<0.05,{ }^{+} p<0.1$

\begin{tabular}{|c|c|c|c|c|}
\hline \multirow[t]{2}{*}{ Variables } & \multicolumn{2}{|c|}{ Parity one } & \multicolumn{2}{|c|}{ Parity two } \\
\hline & Yes & Unsure & Yes & Unsure \\
\hline \multicolumn{5}{|c|}{ Father's leave: (Reference: plan to take leave) } \\
\hline Currently on leave & 0.83 & $0.48^{+}$ & $0.07 * *$ & $0.87 *$ \\
\hline Have taken in the past & 0.82 & 0.59 & $0.06^{* * *}$ & 0.97 \\
\hline No experience, no plan & 0.97 & 1.04 & $0.08 * * *$ & 0.83 \\
\hline Father age & 0.96 & 0.96 & 0.92 & 1.00 \\
\hline Wife age & 0.95 & $0.92 *$ & 0.98 & $0.85 * *$ \\
\hline Father university degree & 1.15 & 1.09 & 0.81 & 0.70 \\
\hline Wife university degree & 0.95 & 1.02 & 1.78 & 0.98 \\
\hline Household income & 1.00 & 1.00 & $0.99 * *$ & $1.00^{+}$ \\
\hline Individual income & 1.00 & 1.00 & 1.00 & 1.00 \\
\hline Age of youngest child & $0.60 * * *$ & $0.69 * * *$ & 0.97 & 0.93 \\
\hline Wife is pregnant & 0.67 & $0.17 * * *$ & 1.21 & 0.00 \\
\hline Observations & 575 & & 351 & \\
\hline Pseudo $R$-squared & 0.11 & & 0.13 & \\
\hline
\end{tabular}

$* * * p<0.001, * * p<0.01, * p<0.05,{ }^{+} p<0.1$

the full demands of childcare. Here, it should be noted that the implicit premise of having a second child for these fathers was that they would continue to be actively involved in childcare as they were for their first child. Given this, having a second child and further forgoing sleep, time, and career entailed a line they were not willing to cross. These are considerations that would be less relevant, if 
Table 9 Relative risk ratio (RRR) of the couple's intention for another child by leave uptake, restricted sample of fathers whose youngest child is three or younger
Table 10 Relative risk ratio (RRR) of the couple's intention for another child by leave uptake, comparing only those who have taken leave and those who will take first leave shortly (reference)

\begin{tabular}{llllll}
\hline Variables & \multicolumn{2}{l}{ Parity one } & & \multicolumn{2}{l}{ Parity two } \\
\cline { 2 - 3 } \cline { 5 - 6 } \cline { 5 - 6 } & Yes & Unsure & & Yes & Unsure \\
\hline Father's leave: (Reference: plan to take leave) & & \\
Currently on leave & 0.74 & $0.45^{+}$ & & $0.03^{* *}$ & $1.14^{*}$ \\
Have taken in the past & 0.72 & 0.50 & & $0.04^{* * *}$ & 1.54 \\
No experience, no plan & 0.85 & 0.88 & & $0.09 * *$ & 1.82 \\
Father age & 0.95 & 0.94 & & 0.97 & 1.01 \\
Wife age & 0.96 & 0.95 & & 0.98 & $0.83^{* *}$ \\
Father university degree & 1.05 & 0.98 & & 1.29 & 0.79 \\
Wife university degree & 1.00 & 1.02 & & 1.43 & 0.74 \\
Household income & 1.00 & 1.00 & & $1.00^{*}$ & $1.00^{*}$ \\
Individual income & 1.00 & 1.00 & & 1.00 & $1.00^{*}$ \\
Age of youngest child & $0.59 * * *$ & $0.69 * *$ & 1.14 & 1.02 \\
Wife is pregnant & $0.51^{*}$ & $0.11^{* * *}$ & & 0.64 & 0.00 \\
Observations & 483 & & 265 & \\
Pseudo $R$-squared & 0.08 & & 0.15 & \\
\hline
\end{tabular}

$* * * p<0.001, * * p<0.01,{ }^{*} p<0.05,{ }^{+} p<0.1$

\begin{tabular}{|c|c|c|c|c|}
\hline \multirow[t]{2}{*}{ Variables } & \multicolumn{2}{|c|}{ Parity one } & \multicolumn{2}{|c|}{ Parity two } \\
\hline & Yes & Unsure & Yes & Unsure \\
\hline \multicolumn{5}{|c|}{ Father's leave: (Reference: plan to take leave) } \\
\hline Have taken in the past & 0.80 & 0.71 & $0.06 * *$ & 0.74 \\
\hline Father age & 1.01 & 1.02 & 0.95 & 0.96 \\
\hline Wife age & 0.95 & $0.89^{+}$ & 1.04 & 0.88 \\
\hline Father university degree & 1.09 & 1.23 & 0.32 & 0.98 \\
\hline Wife university degree & $0.25 * *$ & $0.40^{+}$ & $8.16^{+}$ & 2.88 \\
\hline Household income & 1.00 & 1.00 & $0.99 *$ & 1.00 \\
\hline Individual income & 1.00 & 1.00 & 1.00 & 1.00 \\
\hline Age of youngest child & $0.56 * * *$ & $0.63 * *$ & 0.82 & 1.02 \\
\hline Wife is pregnant & 1.07 & $0.21 *$ & 1.69 & 0.00 \\
\hline Observations & 246 & & 161 & \\
\hline Pseudo $R$-squared & 0.16 & & 0.18 & \\
\hline
\end{tabular}

$* * * p<0.001, * * p<0.01, * p<0.05,{ }^{+} p<0.1$

at all, for fathers not playing a significant role in caregiving and, thus, experiencing limited change to their lives even with an additional child.

Parental leave is not taken in a vacuum, so it is important to consider the fathers' discussion of the broader context in which they took parental leave. Notably, most fathers explained their decision to take leave as a "last resort," faced with no other ways to arrange reliable childcare for a young child-for instance, 
many mentioned how the grandmothers of the child lived too far away or were ill and how they do not want strangers taking care of their baby. Some even stated that they would not have taken leave if their mothers or in-laws were able to help care for their child. Fathers also stressed how overworked they were; many had worked for years without ever getting a proper break or being able to properly spend time with their family. We could then perhaps understand fathers taking leave where only a minority of fathers do as an indication of high levels of difficulty and a lack of alternative measures in reconciling childcare with paid work.

Moreover, many fathers lamented the lack of social support, financial and otherwise, in discussing the constraints to bearing and rearing children. Several described raising a child as "fighting individual battles." Below I introduce two fathers whose accounts capture such sentiments. Inwoo, a blue-collar worker was taking leave to look after his newborn baby as well as his wife who was also taking a break from employment. Sangyoon and his wife were both teachers and while Sangyoon's wife had taken 2.5 years of leave after their first child; they were on leave together after the arrival of their second child. Together these anecdotes illustrate that the current level of childcare support, including the wage replacement and job protection elements of parental leave, fails to signal assurance to parents.

The state support is far from adequate. What I feel being on parental leave is that the policy only offers a way for dual-earning couples to barely get by raising children without dying. ... We are both not in employment at the moment, so the level of financial support is ridiculous, and unlike large companies, (at small companies) there is no guarantee of returning to work... (Inwoo, father of one)

The individual has to be responsible for most of the costs that come with raising a child... But for people who can't afford these things at all, it must be so much harder and even feel shameful to raise a child. If state support can be expanded and people start feeling, 'it's doable with state support', then I think people can start having the confidence to have more children... (Money) won't solve everything but it lets you breathe. (But) I think current parental leave support is seriously insufficient... (Sangyoon, father of two)

While most prominent were stories of fathers who were either firm on having no more children or having second thoughts about having another child after their leave, there were also a group of fathers who ended up having more children than planned, due to unintended pregnancies. In Minjae's (father of two) case, the couple originally wanted just one child and Minjae had taken 17 months of leave for his first child, during when his wife became unintendedly pregnant. At the time of the interview, Minjae was currently on another 2 years of leave for his second child. Minjae noted that his wife now even seems open to the idea of a third child, although he is content with just two. Jaein (father of three), who had taken 12 months of leave for each of his three children, had originally planned on having just one child but ended up with three-all from unintended pregnancies. Daniel (father of one, expecting another) had no plans for a second child at the time of the interview but found out about his wife's pregnancy shortly afterwards, about which he posted on this social 
media. Daniel seemed surprised but happy about the news of the unintended pregnancy, as he was in the case of his first child, who was also born from unintended pregnancy.

My wife mentioned having a third (child) because she feels so happy although we are financially tight. I have no thoughts about a third (child).... (Interviewer: Did you taking leave influence your wife?) Yeah, I think that was big. ... Because I am in charge of most things and I put the kids to sleep and everything, her satisfaction is high... I think she talks about having a third because she doesn't have to worry. - Minjae (father of two)

After (having our first child), it was so exhausting... So I told my friends and colleagues who were married but had no kids that they should have just one child... I raised the child and it was too much work, so we thought we should have just one because it's too difficult. But we ended up having three. - Jaein (father of three)

No plans (for a second child), but that doesn't mean never because you don't necessarily have to have plans. But financially I don't know if we can afford it anymore. I think there are amazing benefits for children to have a sibling, that constant companionship and learning from each other, I think those things are wonderful but just realistically, financially, it's probably not feasible, I'd say. - Daniel (father of one)

The prevalence of fathers who were previously fairly set on just one child going on to have more highlights the tentative, interactive, and to an extent, unpredictable nature of fertility intentions. In the case of unintended pregnancy, attributing causation of additional childbirth to the father having taken leave for the previous child is difficult. However, Minjae's story does highlight that a father's greater involvement in childcare may contribute to his wife's greater openness toward an additional child. As an extension of this, we may cautiously hypothesize that fathers' active involvement in childcare could potentially nudge couples to be more positive about unintended pregnancies. On the other hand, Daniel was not alone in believing two was better than one; many of the interviewed fathers considered having multiple children as more ideal than just one. Such a two-child ideal may also be mediating the otherwise stronger negative impact of fathers' leave experience on intentions for a second child in the case of unintended pregnancy.

As a whole, the qualitative analysis finds that fathers attenuate their fertility intentions for an additional child downwards after experiencing the challenges of childcare during their leave, in line with the findings from the quantitative analysis. In articulating their changed intentions, fathers stressed their newly acquired understanding of the difficulties of childcare. However, the lack of social and institutional support for childcare appeared to be more fundamental factors driving the fathers' aversion toward more children. While the fathers' uptake of leave seemed to contribute to their wives wanting an additional child in very few cases, these feelings were not reciprocated by the fathers, and there was no instance where the father reported increased desires for an additional child after parental leave. Finally, unintended pregnancies took up considerable instances of the 
childbirths that the interviewed fathers talked about. It is, however, too early to be conclusive about the mechanisms between unplanned births and fathers' greater involvement in childcare, whether through parental leave uptake or not. Overall, the findings from the interviews support the conclusion from the quantitative analysis that fathers' leave leads more towards a downward rather than upward adjustment of childbearing intentions.

\section{Discussion and Conclusions}

While gender equity theories of fertility suggest that fathers' uptake of leave would lead to increased fertility, the empirical studies testing this have been limited, mostly to Nordic countries, and somewhat inconsistent in their findings. This research took on the aim of filling lacunas in our current limited knowledge of how fathers' uptake of leave impacts continued fertility by examining South Korean fathers' couple-level intentions for an additional child using mixed methods. In both the quantitative as well as qualitative analysis, I found no evidence that fathers' leave experience has a positive impact on the couple-level intentions for another child. On the contrary, multinomial logistic regressions found evidence for a negative effect of fathers' uptake of leave on fertility intentions, although it was significant only at parity two. The interviewed fathers developed heightened awareness of the difficulties of raising children as well as lack of social support during their leave experience, factors which drove their fertility intentions downwards, though not always their wives.' Qualitative analysis further suggested, though not conclusively, that the two-child norm and unintended pregnancies could be mediating the otherwise stronger negative relationship between fathers' leave experience and intentions for a second child.

How do the findings from this paper compare with previous research on the relationship between fathers' leave and fertility? This study echoes findings from Farré and González (2019) which found fathers' leave to lead to a decrease in men's desired fertility in light of men's increase awareness of the costs of childrearing in Spain. On the other hand, the findings diverge from that of Duvander et al. (2020) In both papers, fathers' uptake of leave is found to have no positive influence on the fertility intentions of those with one child. However, a difference is that my paper finds a negative (though not significant) relationship on the intention for a second child, while Duvander et al. finds a lack of difference in the risk of second births. The divergence in the results seems clearer for parity two, with Duvander et al. finding a limited positive effect and this paper finding a significant negative effect. I consider some differences in national context, research design, and data as well as the methodological limitations of this paper that may explain the different findings.

First, there are stark differences in the level of gender equality, employment hours, and childcare services between South Korea (and Spain) and the Nordic countries. The logic behind gender equality theories of fertility, that men sharing women's burdens to care will result in manageable burdens for everyone, may work in societies which guarantee a certain level of work-family balance. However, this may not be the case in a context where the duty to care historically has been unduly pushed onto families and individualized, with the state playing a minimal role, where the 
provision of reliable public childcare lacks, and where men are already working unusually long hours in paid labor. In such settings, redistributing care duties within the family from the women to the men can only do so much if the basic conditions of work and care are left constant. This is reflected in stories of how fathers of young children consider themselves to be "fighting individual battles" with current levels of state support so "far from adequate." In short, fertility intentions are not formed in a vacuum and the outcomes of similar policies may greatly differ depending on social contexts. If the social conditions are broadly incompatible with childcare, a new fertility equilibrium may not necessarily emerge even when a minority of men partake in "the second half of the gender revolution." Then, the most important policy implication of this research is not that policymakers with pronatalist aims should stop promoting fathers' leave because it appears to be ineffective or even counterproductive in raising fertility. Rather, it suggests that the individual efforts of men to shift the care equilibrium at home by taking parental leave can only play a limited role in incentivizing couples to have more babies or remedying their difficulties in realizing their fertility ideals, as long as more systemic changes in public childcare support and work-family balance accompanies. In this vein, the results from this study have wider implications for other countries in East Asia and Southern and Eastern Europe, countries with levels of gender inequality, labor market structures, and formal childcare systems which may be more comparable to South Korea than Nordic countries.

A second limitation of this research is that it studies couple-level fertility intentions, rather than outcomes. While the use of fertility intentions is considered a reasonably good proxy for fertility outcomes, it is far from perfect especially without temporal specificity, as the qualitative analysis from this paper have shown. Intentions are neither consistent nor static across time; they are subject to revisions, both upwards and downwards (Heiland et al., 2008; Iacovou \& Tavares, 2011; Leifbroer, 2009). Thus, even though fathers reported intention for another child, the intention may not ultimately be actualized. On the contrary, an unintended pregnancy may lead to an additional child where the couple had no such plans. An important case that my quantitative analysis is unable to account for is unintended pregnancies, which not only came up prominently in the interviews but moreover is estimated to take up between a quarter to half of all pregnancies in South Korea (Bahk et al., 2015). Given that around half of unplanned pregnancies are considered to end in abortions in high-income countries (Bearak et al., 2020), for every ten childbirths in South Korea, one or two could be births resulting from unplanned pregnancies. Furthermore, although fathers were asked to report couple-level fertility intentions, it is possible that some couples would not be in agreement about plans for another child. As the qualitative analysis suggests, surveying the wives on the couple-level fertility intentions may have produced a slightly different narrative, with potentially higher intentions or openness for an additional child if the husbands have taken leave. In short, while the measure utilized in this study, of fertility intentions gives insight into the fertility decision-making processes, it is not a perfect proxy for fertility outcomes and should be interpreted with such limitations in mind.

A more critical limitation of particularly the quantitative analysis in this paper is that it is not based on nationally representative data, and thus, the results may not 
accurately represent wider trends at the population level. There could especially be considerable differences between the sample-level and the population-level fathers with neither leave experience nor plan, as this group represents the vast majority of Korean fathers. Furthermore, even though this paper utilized a resourceful means to account for the issue of selection of certain fathers into leave as well as a model which controlled for a range of demographic characteristics, it was not able to control for unobserved heterogeneities. Using panel data to run fixed-effect regressions to track changes in fertility intentions over time would be optimal in controlling for selection effects, given the availability of suitable data. Thus, while the qualitative findings support the quantitative findings that fathers' parental leave seems to have an anti- rather than pronatalist effect, the limitations of the data used for this study should be noted when making broader population-level generalizations.

In addition, it must be recognized that the data collection for this study took place during the COVID19 pandemic, during which parents generally had to burden increased labor for childcare due to the closure of some childcare facilities. However, I did not find notable differences between interviewed fathers who had been on leave during the pandemic and those who had taken (and finished) their leave before the pandemic. Moreover, the impact of the pandemic on childcare experience during leave was not a prominent theme in the interviews, even when the fathers were explicitly asked to talk about it. Nonetheless, I should acknowledge the possibility that the data may be partially biased because of the pandemic setting when generalizing the findings from this study.

In conclusion, findings from this paper suggest that fathers taking leave is associated with fathers' downward attenuation of fertility intentions, consistent with Farré and González (2019). This contrasts with earlier studies of Nordic countries, suggesting that the relationship between fathers' leave and fertility may be very much context specific and that in countries with poor support for the reconciliation of employment and childcare, equalizing the gendered division of parental leave may not be sufficient to see a reversal in its fertility trends. These findings suggest that existing gender equality theories of fertility do not sufficiently consider the multiple and possibly diverging ways that women and men could respond to enhanced gender equality within the family across heterogenous contexts. In countries where the state support for childcare is inadequate and where work-family balance is particularly poor, a gender egalitarian division of parental leave may lead men to open their eyes to the intensive childcaring experience, acting as a demotivation for men wanting more children. Theories of gender equality would, therefore, benefit by reconsidering the role of the state in enabling better work-care balance as well as a more dyadic understanding of fertility decisions.

However, due to a number of methodological limitations, more follow-up studies are needed, ideally with representative data, before we can conclude with more confidence that fathers' leave experience has an anti-natalist impact in certain contexts, namely countries with poor support for the reconciliation of employment and childcare. In particular, tracking leave-taking fathers' and their wives' fertility intentions and outcomes over time with longitudinal quantitative and qualitative data would be particularly valuable. Moreover, leave taking tends to be a more difficult experience for forerunner fathers than for those who follow. It would, thus, be worthwhile 
to conduct follow-up studies in the coming decades, when a greater proportion of fathers take leave and fathers' uptake of leave becomes a norm in South Korea, as it is in Nordic countries. With these considerations in mind, I invite future research on the effect of fathers' uptake of parental leave and gender equality more generally on continued childbirths, ideally with improved data and methods and more diverse country and policy settings.

Funding This research was carried out as part of my doctoral studies, funded by the Cambridge Trust and Murray Edwards College.

Availability of Data and Material Not available due to ethical restrictions (participant consent).

Code Availability Available on request.

\section{Declarations}

Conflicts of interest The author declares that they have no conflict of interests.

Open Access This article is licensed under a Creative Commons Attribution 4.0 International License, which permits use, sharing, adaptation, distribution and reproduction in any medium or format, as long as you give appropriate credit to the original author(s) and the source, provide a link to the Creative Commons licence, and indicate if changes were made. The images or other third party material in this article are included in the article's Creative Commons licence, unless indicated otherwise in a credit line to the material. If material is not included in the article's Creative Commons licence and your intended use is not permitted by statutory regulation or exceeds the permitted use, you will need to obtain permission directly from the copyright holder. To view a copy of this licence, visit http://creativecommons.org/licen ses/by/4.0/.

\section{References}

Bahk, J., Yun, S.-C., Kim, Y.-M., \& Khang, Y.-H. (2015). Impact of unintended pregnancy on maternal mental health: A causal analysis using follow up data of the Panel Study on Korean Children (PSKC). Pregnancy and Children, 15(85), 1-12.

Bearak, J., Popinchalk, A., Ganatra, B., Moller, A.-B., Tunçalp, Ö., Beavin, C., Kwok, L., \& Alkema, L. (2020). (2020) Unintended pregnancy and abortion by income, region, and the legal status of abortion: Estimates from a comprehensive model for 1990-2019. Lancet Global Health, 8, e1152-e1161.

Billari, F. C., Phillipov, D., \& Testa, M. R. (2009). Attitudes, norms, and perceived behavioural control: Explaining fertility intentions in Bulgaria. European Journal of Population, 25, 439-465.

Bünning, M. (2015). What happens after the 'daddy months'? Fathers' involvement in paid work, childcare, and housework after taking parental leave in Germany. European Sociological Review, 31(6), $738-748$.

Chen, M., \& Yip, P. S. F. (2017). The discrepancy between ideal and actual parity in Hong Kong: Fertility desire, intention, and behavior. Population Research Policy Review, 26, 583-605.

Cools, S., Fiva, J. H., \& Kirkebøen, L. J. (2015). Causal effects of paternity leave on children and parents. Scandinavian Journal of Economics, 117(3), 801-828.

Duvander, A.-Z., \& Andersson, G. (2006). Gender equality and fertility in Sweden. Marriage and Family Review, 39(1-2), 121-142.

Duvander, A.-Z., Lappegård, T., \& Andersson, G. (2010). Family policy and fertility: Fathers' and mothers' use of parental leave and continued childbearing in Norway and Sweden. Journal of European Social Policy, 20(1), 45-57. 
Duvander, A.-Z., Lappegård, T., \& Johansson, M. (2020). Impact of a reform towards shared parental leave on continued fertility in Norway and Sweden. Population Research and Policy Review, 39, 1205-1229.

Duvander, A.-Z., Lappegård, T., Andersen, S. N., Garðarsdóttir, O., Neyer, G., \& Viklund, I. (2019). Gender equal family policy and continued childbearing in Iceland. Norway and Sweden. Demographic Research, 40(51), 1501-1528.

Esping-Anderson, G., \& Billari, F. C. (2015). Re-theorizing family demographics. Population and Development Review, 41(1), 1-31.

Farré, L., \& González, L. (2019). Does paternity leave reduce fertility? Journal of Public Economics, 172, 52-66.

Goldscheider, F., Bernhardt, E., \& Lappegård, T. (2015). The gender revolution: A framework for understanding changing family and demographic behavior. Population and Development Review, 41, 207-239.

Hart, R. K., Andersen, S. N., \& Drange, N. (2019). Effects of extended paternity leave on union stability and fertility. Statistics Norway, Discussion Papers No. 899.

Heiland, F., Prskawetz, A., \& Sanderson, W. C. (2008). Are individuals' desired family sizes stable? Evidence from West German Panel Data. European Journal of Population, 24, 129-156.

Iacovou, M., \& Tavares, L. P. (2011). Yearning, learning, and conceding, reasons men and women change their childbearing intentions. Population and Development Review, 37(1), 89-123.

International Network on Leave Policies and Research. (2019). 15th International review of leave policies and related research. Retrieved from https://www.leavenetwork.org/fileadmin/user_upload/ k_leavenetwork/annual_reviews/2019/2._2019_Compiled_Report_2019_0824-.pdf.

Ito, D., \& Todoroki, M. (2020). Evaluating the quality of online survey data collected in 2018 in the USA: Univariate, bivariate, and multivariate analyses. International Journal of Japanese Sociology, 30(1), 140-162.

KIHASA. (2019). National study of fertility and family health and welfare. Retrieved from https:// gsis.kwdi.re.kr/statHtml/statHtml.do?orgId=338\&tblId=DT_1BC2809N\#.

Kim, J. W., \& Choi, Y. J. (2012). Farewell to old legacies? The introduction of long-term care insurance in South Korea. Ageing \&amp; Society, 33(5), 871-887.

Lappegård, T. (2010). Family policies and fertility in Norway. European Journal of Population, 26(1), 99-116.

Lee, J. W., Lee, J. L., Do, N. H., Choi, H. M., Lee, J. H., Lee, Y. J., Woon, J. Y., \& Yeom, H. K. (2018). Survey on the current status of nationwide childcare in 2018. Ministry of Health and Welfare.

Lee, S. (2017). Demographic dynamics and policy response. Health and Welfare Policy Forum, 243, $29-46$.

Liefbroer, A. C. (2009). Changes in family size intentions across young adulthood: A life-course perspective. European Journal of Population, 25, 263-386.

Livi-Bacci, M. (2001). Desired family size and the future course of fertility. Population and Development Review, 27, 282-289.

McDonald, P. F. (2000a). Gender equity in theories of fertility transition. Population and Development Review, 26(3), 427-439.

McDonald, P. F. (2000b). Gender equity, social institutions and the future of fertility. Journal of Population Research, 17(1), 1-16.

McDonald, P. F. (2006). Low fertility and the state: The efficacy of policy. Population and Development Review, 32(3), 485-510.

McDonald, P. F. (2013). Societal foundations for explaining low fertility: Gender equity. Demographic Research, 28, 981-994.

Miettinen, A., Basten, S., \& Rotkirch, A. (2011). Gender equality and fertility intentions revisited: Evidence from Findland. Demographic Research, 24(20), 469-496.

Morgan, S. P., \& Rackin, H. (2010). The correspondence between fertility intentions and behavior in the United States. Population and Development Review, 36(1), 91-118.

National Assembly Budget Office. (2019). An analysis of the characteristics and projections of financing for childcare support projects.

NOSOCO (Nordic Statistical Committee). (2017). Social protection in the Nordic countries: Scope, expenditure and financing.

OECD. (2017). OECD family database. PF2.2 Use of childbirth-related leave benefits. Retrieved from https://www.oecd.org/els/family/PF2-2-Use-childbirth-leave.pdf. 
OECD. (2019). OECD family database. PF2.4 Parental leave replacement rates. Retrieved from https://www.oecd.org/els/family/PF2_4_Parental_leave_replacement_rates.pdf.

OECD. (2021a). Hours worked (indicator). https://doi.org/10.1787/47be1c78-en.

OECD. (2021b). Time spent in paid and unpaid work, by sex. Retrieved from https://stats.oecd.org/ index.aspx?queryid $=54757 \#$.

Okun, B. S., \& Raz-Yurovich, L. (2018). Housework, gender role attitudes, and couples' fertility intentions: Reconsidering men's roles in gender theories of family change. Population and Development Review, 45, 169-196.

Oláh, L. S. (2003). Gendering Fertility: Second births in Sweden and Hungary. Population Research and Policy Review, 22, 171-200.

Pailhé, A., Solaz, A., and Tô. M., 2018. Can daddies learn how to change nappies? Evidence from a short paternity leave policy. Working Papers 240. French Institute for Demographic Studies.

Patnaik, A. (2019). Reserving time for daddy: The consequences of fathers' quotas. Journal of Labor Economics, 37(4), 1009-1059.

Philipov, D., Speder, Z., \& Billari, F. C. (2006). Soon, later, or ever? The impact of anomie and social capital on fertility intentions in Bulgaria (2002) and Hungary (2001). Population Studies, 60(3), 289-308.

Raybould, A., \& Sear, R. (2020). Children of the (gender) revolution: A theoretical and empirical synthesis of how gendered division of labour influences fertility. Population Studies, 75, 169-190.

Schober, P. S. (2014). Parental leave and domestic work of mothers and fathers: A longitudinal study of two reforms in West Germany. Journal of Social Policy, 43(2), 351-372.

Schoen, R., Astone, N. M., Kim, Y. J., Nathanson, C. A., \& Fields, J. M. (1999). Do fertility intentions affect fertility behavior? Journal of Marriage and the Family, 61, 760-799.

Statistics Korea. (2020a). Childcare statistics. Retrieved from https://www.index.go.kr/potal/main/EachD tlPageDetail.do?idx_cd=1583.

Statistics Korea. (2020b). Household finances and living conditions study. Retrieved from https://www. index.go.kr/potal/main/EachDtlPageDetail.do?idx_cd=2762.

Statistics Korea. (2020c). Statistics of parental leave in 2019 (provisional).

Statistics Korea. (2020d). Study on the economically active population. Retrieved from https://kosis.kr/ statHtml/statHtml.do?orgId=101\&tblId=DT_1DA7012S.

Statistics Korea. (2020e). Time-use survey. Retrieved from http://www.index.go.kr/potal/stts/idxMain/ selectPoSttsIdxMainPrint.do?idx_cd=3027\&board_cd=INDX_001.

Statistics Korea. (2021a). Educational admissions and entrance rate. Retrieved from https://www.index. go.kr/potal/main/EachDtlPageDetail.do?idx_cd=1520.

Statistics Korea. (2021b). 2020 Population trends study: Provisional results.

Sobotka, T., \& Beaujouan, E. (2014). Two is best? The persistence of a two-child family ideal in Europe. Population and Development Review, 40(3), 391-419.

Tamm, M. (2019). Fathers' parental leave-taking, childcare involvement and labour market participation. Labour Economics, 59, 184-197.

Testa, M. R., \& Bolano, D. (2021). When partners' disagreement prevents childbearing: A couple-level analysis in Australia. Demographic Research, 44(33), 811-838.

Wray, D. (2020). Paternity leave and fathers' responsibility: Evidence from a natural experiment in Canada. Journal of Marriage and Family, 82, 534-549.

Publisher's Note Springer Nature remains neutral with regard to jurisdictional claims in published maps and institutional affiliations. 